\title{
THE EFFECT OF PERCUSSION OF NERVE
}

\author{
BY \\ D. DENNY-BROWN and CHARLES BRENNER *
}

(Received 8Th August, 1944)

THAT a physical impact or blow on a peripheral nerve may cause a brief and transient disorder of neural function has long been recognized. The mildest forms of such disturbance, such as occur when the ulnar nerve at the elbow is knocked, are within the experience of all. Tillaux (1866) and other early writers distinguished further degrees of commotion and contusion, but did not always distinguish transient lesions following brief impact from those associated with more prolonged physical force such as the damage to the brachial plexus resulting from dislocation of the shoulder, which were also spoken of as "commotion." Weir Mitchell (1872) speaks of contusion as resulting from a blow from a blunt instrument, and, noting that the immediate effects are transient, emphasizes the liability to delayed neuralgia, and in some cases to paralysis with delayed onset. He also noted that, as a result of mild contusions, the disturbance of function was partial, and involved sensory function more than motor.

Tubby (1915) describes " concussion " as varying from effusion of blood into a nerve to temporary anæmia or hyperæmia resulting from compression of a nerve against bone by the rapid passage of a projectile, and cites case histories illustrating the transient paralysis lasting 5, 7 and 11 weeks before complete recovery (the last an injury of the sciatic nerve at the notch) without reaction of degeneration, and with both motor and sensory changes. He also described two examples of lesions of mixed severity where some muscles, delayed in recovery, had lost faradic excitability.

In the World War 1914-18 a proportion of the nerves damaged by gunshot wound presented a fusiform enlargement, a "nerve spindle" or "pseudo-neuroma", (Tinel, 1917). Platt (1921) found such a lesion in 7 per cent. of 500 operations. The condition is also referred to in the British Medical Research Council Report (1920). Whereas asymmetrical lesion of the nerve, or extensive fibrosis covering a wide extent, may be attributed to direct laceration of the nerve by the injury or to involvement in subsequent sepsis, the nerve spindle was supposed to result from a primary contusion of the nerve by the transient passage of the projectile. It was no doubt often

* From the Neurological Unit, Boston City Hospital, and the Department of Nervous Diseases, Harvard Medical School. difficult to decide upon the actual mechanism of injury, and Dejerine et al. (1915) remark that the symptoms of "compression" most often had appeared at the actual moment of injury. Platt (1921) concludes that war lesion of nerves is almost always a "primary lesion" and the secondary influence of compression by perineural scarring or callus " is usually subordinate and often entirely negligible.",

Tinel (1917) summarizes the findings of Dejerine and his collaborators (1915) and describes two types of nerve lesions in continuity, a neuroma or cicatrix with axonal proliferation proximal to a dense intraneural scar, and a pseudo-neuroma occurring " in certain contusions or compressions" of nerve when the laminated peripheral sheaths were not destroyed. In the latter condition he described swelling or fragmentation of the myelin, with frequent demyelination of the fibres. The axis cylinders were irregular, beaded, barbed, or in the form of a bundle of fine fibrils. There was always an interstitial infiltration of the nerve with " connective tissue" and proliferation of the sheath of Schwann. In the region of the swelling the myelin may have disappeared without interruption of axis cylinders, and without Wallerian degeneration, in other cases fibres had degenerated. He noted the association of incomplete, temporary, dissociated and irregular paralyses with such lesions. He also stated that in other cases regeneration was slow and difficult. The "syndrome of nerve irritation accompanied by trophic pains and disturbances", (causalgia) was common in association with such lesions as was also the experience of Platt (1921). In two cases of median causalgia under the care of one of us (D. D-B.) the original disorder in motor function of the median nerve following gunshot injury had been so transient as to lead to the inevitable conclusion that the primary nerve injury was a contusion. Contusion of nerve therefore has a possible but unknown part in the pathogenesis of causalgia and offers a simple starting point in this problem.

Tillaux (1866) subjected the nerves of rabbits to slight blows with a hammer and then examined the contused portion. Four days after the blow he saw hæmorrhages within the epineurium and under the perineurium, and lessening of the calibre of nerve fibres, with commencing distal degeneration. 
Weir Mitchell (1872) cites experiments on rabbits and observed that in lesser degrees of injury many fibres escaped damage. After a "smart blow" there was immediate complete paralysis and the nerve fibres at the level struck had an irregularly swollen appearance. Complete functional and structural recovery could occur in a few days. In two rabbits allowed to survive a longer period a " neuroma" developed at the site of injury. Cajal (1928) made a detailed study of the regenerative changes following a closely similar injury caused by a brief pinch of a nerve by forceps, and described necrosis of the damaged portion of the axon and rich branching of nerve sprouts within the undamaged sheath of Schwann.

In view of some doubt concerning the nature of the structural change underlying the very brief disturbance of function in lesser degrees of such lesion as described by Mitchell and others, and the relationship of such damage to that described by us in lesions of nerve caused by ischæmia and compression (Denny-Brown and Brenner 1944a and $b$ ) we have repeated the experiments of Tillaux and Mitchell in cats and made observations at varying intervals after injury.

\section{Method}

The sciatic nerve of the cat was exposed in midthigh under nembutal anæsthesia. The nerve was gently raised on a flat metal surface (at $P$ in the diagram Fig. 1) and the blunt edge of a retractor

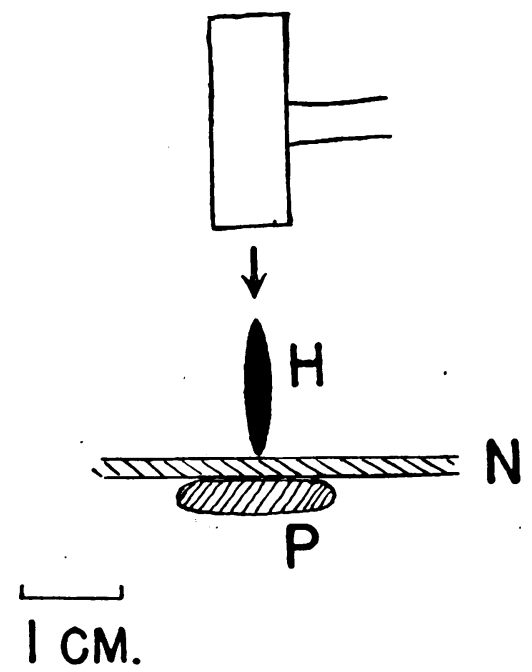

Fig. 1.-Diagram to show cross-section shape of the striker $H$, drawn to scale, in relation to the nerve $N$ and underlying plate $\mathbf{P}$.

handle (cross-section to scale shown in Fig. 1 at $\mathbf{H}$ ) was laid transversely across the nerve, and struck a sharp blow with a light hammer. On removing the instruments a narrow groove is immediately seen. The depth of the groove depends on the intensity of the blow. Our intention was to give just sufficient injury to leave a visible transverse mark on the nerve. In the next 30 seconds the nerve bordering the groove became distinctly pale and opaque, even if no hæmorrhage occurred. Within 8 to 15 seconds one or two very small streaks of hæmorrhage were often seen alongside the largest vessels on the nerve at the site of injury. Within the next few minutes the groove filled out, the pallor disappeared, and no further hæmorrhages occurred. The intensity of blow used was not such as to induce hæmorrhage within any nerve bundle except in some control experiments in which hæmorrhage within the perineurium was especially sought. An instrument with more rounded edge had to be used to produce this effect. The wound was then closed aseptically and the animal observed daily for evidence of impairment of movement or sensation. Before sacrifice the wound was re-opened under light nembutal anæsthesia and the nerve stimulated above and below the damaged region. The animal was then killed, the nerve fixed in formol-saline and stained by osmic acid, Gros-Bielschowsky method, cresyl-violet, Sudan III, Spielmeyer's myelin stain, iron hæmatoxylin and other methods.

\section{Persistent Paralysis}

\section{Findings}

Percussion of nerve sufficient to impair conduction in some degree is followed by the appearance of a swelling (pseudo-neuroma) of the region of percussion (Fig. 2). If the percussion is so light that no disturbance of motor function is demonstrable, a few fibres in the nerve may be later found to have been damaged, but no swelling occurred in these circumstances in any of five experiments. It is convenient first to examine the disorder produced by a degree of trauma sufficient to lead to immediate loss of conduction of movement persisting for six weeks or longer, with Wallerian degeneration below the lesion. The changes were identical whether small hæmorrhages had occurred at the time of injury or not. If rupture of the perineurium occurred, additional changes appeared and these will be described in a separate section. Motor paralysis below this type of lesion was complete, but some reaction to a pinch of the pads of the toes always remained and in one experiment to a touch, showing that some pain conduction and sometimes touch conduction also was intact. Detailed observations on sweating and temperature were not made, but no gross change was observed.

Histological examination of the nerve within the first 24 hours after a severe degree of injury failed to demonstrate any change in the myelin or axis cylinders. Twenty-four hours after the injury the injured region of the nerve was swollen and œedematous. The myelin sheath of each fibre was greatly swollen throughout the odematous region and the myelin irregular. Within three days most of the myelin at the level of percussion and for a distance of one or two millimetres above and below had disappeared. Large numbers of phagocytic histiocytes, containing fat granules, filled the odematous endoneural spaces. Some vacuolar masses, staining faintly with fat stains, adhered to remnants of 

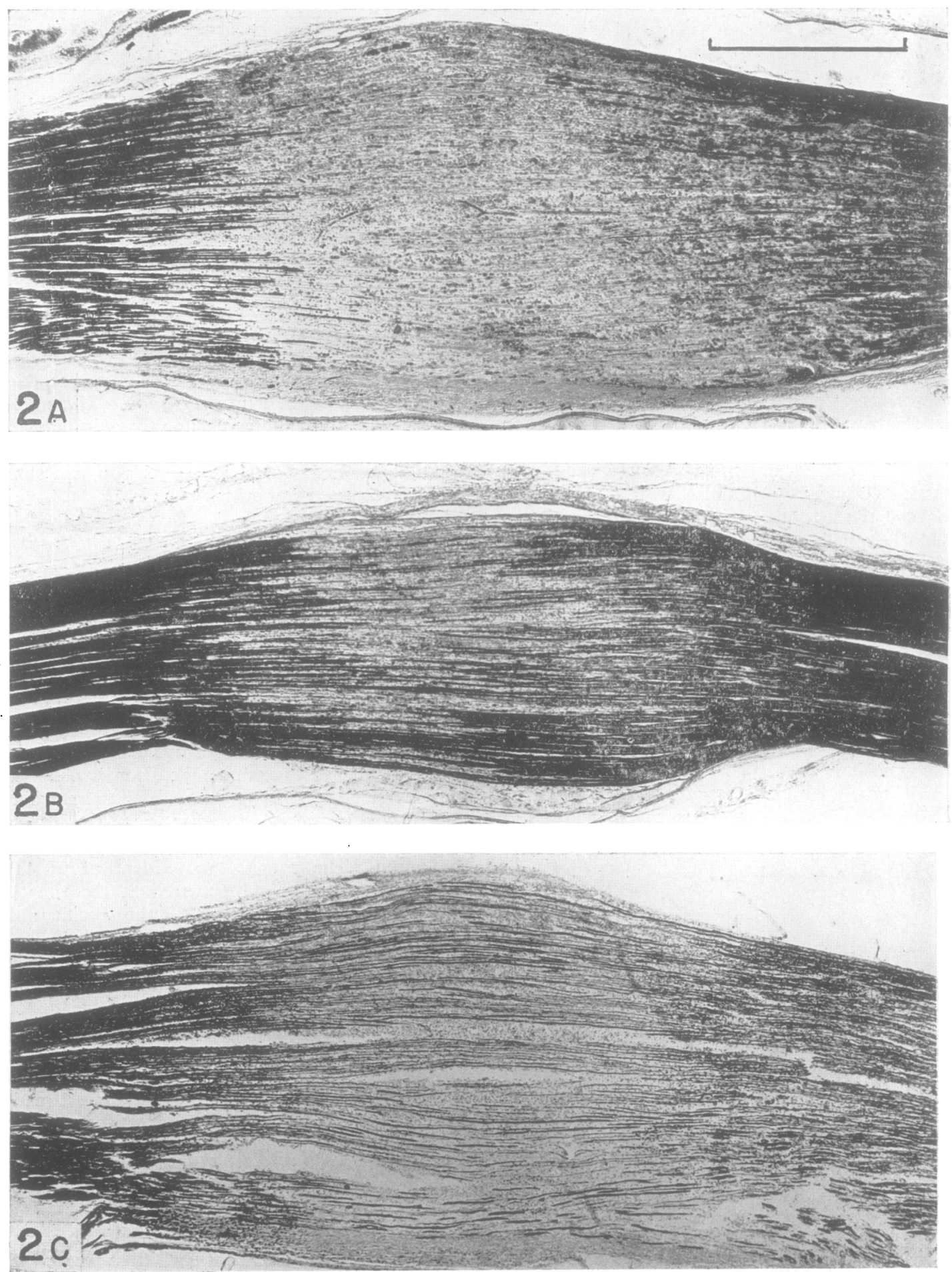

Fig. 2A.-Longitudinal section through the pseudo-neuroma, popliteal nerve, 13 days after injury. Complete motor paralysis, with sensation to pinch and touch persisted from time of injury. Electrical excitability of peripheral motor branches of the nerve was completely lost. Spielmeyer's stain for myelin. The left of the figure is proximal and right distal in all figures of longitudinal section. The ruled line in upper corner is equivalent to $1.0 \mathrm{~mm}$.

Fig. 2B.-Popliteal nerve, 13 days after injury. Great weakness of plantar flexion for three days with preservation of sensation to pinch or touch throughout. Spielmeyer's stain. Magnification as in A.

Fig. 2C.-As 2B, Gros-Bielschowsky method for axis cylinders. 

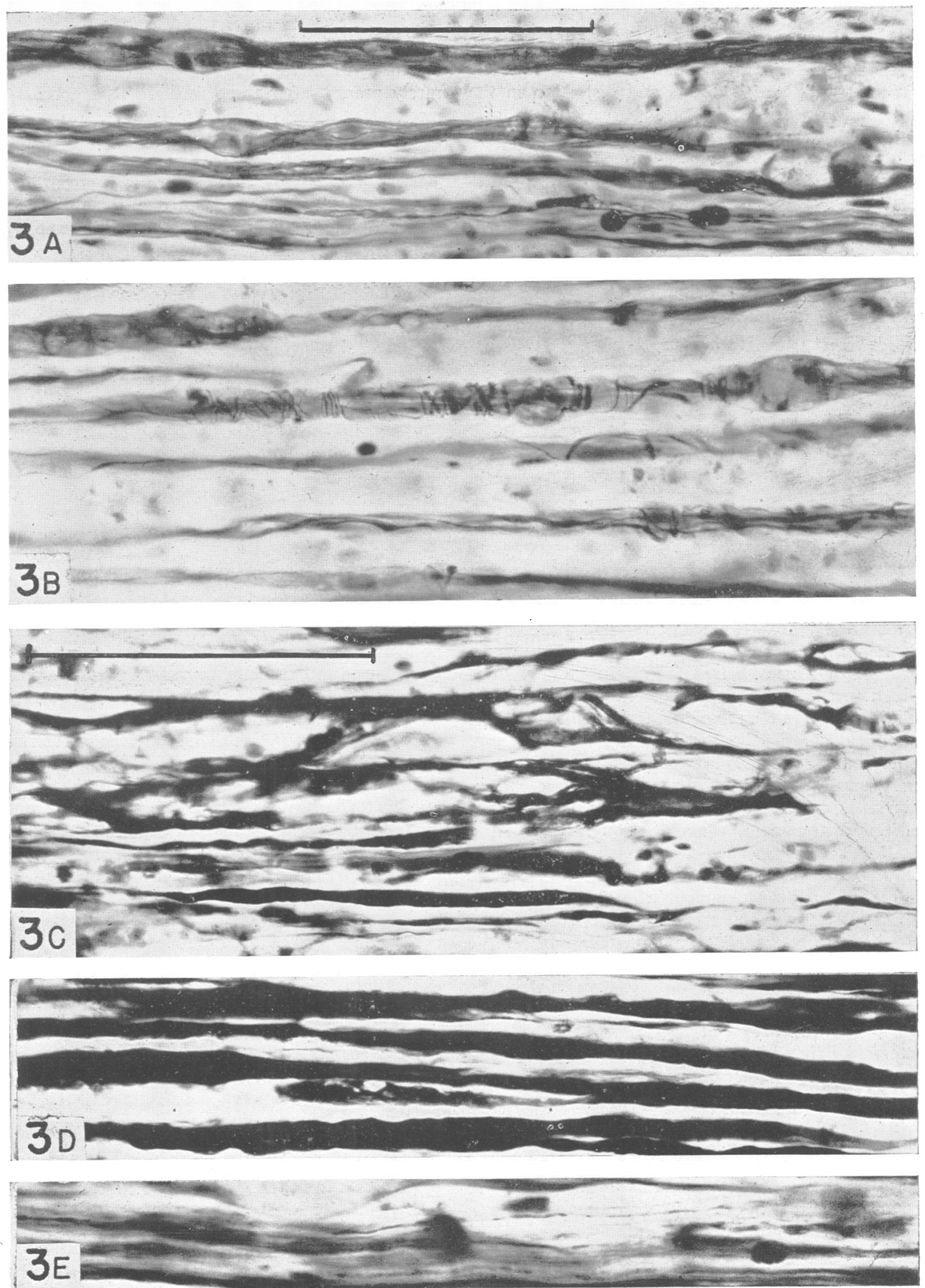

Fig. 3A.-Bundles of regenerating fibrils in the centre of the pseudo-neuroma, same experiment as $2 \mathrm{~A}, 13$ days after injury. Gros-Bielschowsky method, counterstained Sudan III and hæmatoxylin. The ruled line at the top of the figure is equivalent to $0.1 \mathrm{~mm}$.

FIG. 3B.-As 3A, to show detail of branching of parent axis cylinder. The uppermost fibre loses the myelin sheath between the left and middle thirds of the figure. The remaining fibres are unmyelinated. Magnification is as in $A$. FIG. 3c.-Axis cylinders just proximal to the level of percussion which begins at the right of the figure, three days after injury. Gros-Bielschowsky method. The ruled line at upper left corner is equivalent to $0 \cdot 1 \mathrm{~mm}$.

FIG. 3D.-As 3C, axis cylinders just distal to the level of percussion. Magnification as in C.

FIG. 3E.-Beading of non-medullated fibres 13 days after severe percussion. Gros-Bielschowsky. 
the Schwann tube. The axis cylinders were greatly swollen, with irregular gaps and distortion in the proximal part of the œdematous area (Fig. 3c) and more regular expansion in the distal swelling (Fig. 3D). At the point of percussion all the larger axis cylinders ended in large bulbs or knobs, in the manner clearly described by Cajal (1928) in his account of trauma to nerve by pinch with forceps. For a millimetre above this, the axis cylinder had sprouted long leashes and whorls of fine fibrils (Fig. 3c), many of which had already forced their way into the empty Schwann tube for a millimetre or more. Others appeared to splay out into the endoneural spaces. Many of the finer axons were simply beaded and irregular in calibre as they passed the percussed region. Distal to the percussion the myelin and axis cylinders showed only the earliest signs of Wallerian degeneration.

Fourteen days after the injury such a nerve was invariably swollen at the site of injury, sometimes to as much as twice the diameter of the trunk above and below. The swelling consisted of a localized œdematous zone in which the nerve fibre strands were widely separated by fluid containing many histiocytes loaded with fat granules (Fig. 2A). The myelin had entirely disappeared in the centre of this swollen region, and the nerve fibres were represented by chains of Schwann nuclei in almost all of which multiple strands of regnerating nerve fibrils (Fig. 3A), and in the remainder a single axis cylinder, extended completely across the swollen region. These bands of fibrils lay relatively isolated by the endoneural œdema. Nuclear stains such as hæmatoxylin or cresyl violet showed the bands as bundles of nuclei traversing the œdematous region, and Laidlaw's stain revealed that each had a covering of endoneural reticulum.

Tráced to the proximal myelin sheath the axon fibrils were found to spring from the stump of the old axon, either as a spray immediately below the last myelin or more commonly as the result of repeated sprouts from the old axon which was seen to run a variable distance as a pale unmyelinated single central core with sparse Schwann cells at intervals (Fig. 3B). Hæmatoxylin stains revealed an additional outer covering of scattered pale endoneural nuclei. At the point of division the axon was shrunken and stained darkly with silver. Few old axis cylinders passed the centre of the swelling and these branched before reaching the peripheral zone of Wallerian degeneration. A puzzling feature of such proliferating fibrils was their frequent grouping around a larger central fibre which at first appeared to be the persisting original axon. When traceable into the distal segment of the nerve such large axons coursed irregularly around ovoids of degenerated myelin in the old Schwann tube. Close examination convinced us that this appearance of persistence of the original axon at the 14-day stage was due to early maturation of a main regenerative axonic sprout, and that even at this time the profuse networks and spirals of finer fibrils were in process of resorption, for though common at the 14-day stage they were rarely present after three weeks. This process of resorption also explained the frequent occurrence at 14 days of side branches lying outside the sheath of Schwann and directed proximally (Fig. 3A). Bundles of non-medullated fibres appeared either to be intact but with frequent oval swellings, as in FIG. 6F, or to be beaded and irregular where they passed the axis of the pseudo-neuroma (Fig. 3E). On close examination a number of the thinnest medullated fibres were found to run far into the œdematous area before losing their myelin which they regained after 0.2 to $0.5 \mathrm{~mm}$. and coursed distally without Wallerian degeneration. Five of these were in the section shown in Fig. 2A, but are too small to appear in reproduction. Silver stains showed corresponding thin single conductors with associated sheath nuclei, but it was difficult to distinguish these from regeneration except in two instances where such an axon was traced into a small distal intact myelin sheath.

After two weeks the loss of myelin in general coincided with the extent of the swelling both proximally and distally (Fig. 2A). More proximally the myelin sheaths were irregular and swollen for a further $5 \mathrm{~mm}$., with corresponding irregularity and swelling of the contained axis cylinders. This irregularity and swelling we have found associated with simple œdema of nerve (Denny-Brown and Brenner (1944b)) and regard it here as resulting also from œdema. The distal portions of the nerve were in Wallerian degeneration. The myelin and axis cylinders were partly broken up into the familiar ovoids. The heavy content of fat and large fragments of undigested myelin in the whole peripheral segment was in marked contrast to the fine intracellular droplets in the traumatic swelling, described above.

The perineurium was in places lifted from the nerve bundles by fluid containing fat-laden phagocytes. This perineural œdema was variable in degree and never intense. There was no evidence of migration of macrophages or fluid proximally or distally from the swelling. The swelling of the nerve in such a lesion was associated with a localized stasis and congestion of all the vessels in the area. In the region of the nerve just distal to the traumatic swelling the regenerating neurofibrils were seen to pass directly into the degenerating Schwann sheath, coursing irregularly round the obstacles provided by ovoids and fat droplets (Fig. 3A).

After twelve weeks, the swelling at the site of trauma still persisted but was slight in degree. In an experiment where severe weakness, with retained sensation only to a severe pinch, had persisted for 30 days, with full recovery of spreading of the toes delayed until the eighth week, full regeneration had occurred. The regenerated fibres had each a separate sheath of Schwann, with commencing myelination, both in the swelling and beyond. No Perroncito spirals remained in the traumatic swelling. As shown in the two upper fibres in Fig. 8A, a few very small spiral branches besides the 
original conductor had become medullated. This was the exception and no other trace remained of the rich branching that was seen in the first two weeks. It is assumed that most of the young fibres are subsequently resorbed, for the nerve contained few more fibres than just above the lesion. The perineurium was not thickened and there was no epineural change. There was, however, a persistent increase in the oval endoneural cells, which in a section stained with cresyl violet or other nuclear stain was seen to be limited to the region of previous percussion, and to be only very slight in the previously degenerated peripheral segments of the nerve. Associated with this nuclear increase was an intensification of the endoneural reticulum as revealed by Laidlaw's stain. The whole disturbance was much less severe than that caused by crushing the nerve with a hæmostat at the same level, and the onset of recovery is earlier. The completion of final recovery is, however, about the same for both types of lesion.

A complete transverse lesion of nerve caused by percussion is therefore remarkable in the speed of development of a localized swelling at the site of trauma, the rapid removal of myelin from the region of swelling and the relative escape of non-medullated and a few finely medullated fibres. Regeneration is precocious, but once the distal segment of nerve is reached proceeds as after any other interruption with a fairly complete ultimate reconstruction of the nerve. An increase of endoneural reticulum and nuclei marked the region of previous trauma.

\section{Transient Paralysis}

An intensity of blow sufficient to leave an immediately visible indentation on the nerve trunk and occasionally the appearance of a small pin point effusion of blood in the coats of one or more of the larger vessels in the nerve sheath may nevertheless not cause persistent paralysis. We have not attempted to measure the exact intensity of percussion causing such transient effects, for intensity depends on a number of factors which are difficult to determine, such as surface area struck and compressibility of the nerve. It was, however, found that within a wide range of intensities a light percussion would cause an immediate motor paralysis usually complete for dorsiflexion of the foot and spreading, and partial for plantarflexion, lasting three to four days, followed by rapid recovery in the next 48 hours. Spreading of the toes was always the most severely affected motor function in partial lesions and the last to recover in all lesions. There was no loss of sensation when the animal was first examined on recovery from anæsthetic 18 hours after the injury. The foot was even slightly hyperæsthetic to a light touch in the first three days. If pain sense appeared impaired in any degree, there was invariably also some persistent weakness, lasting more than two weeks. The nerve was explored, stimulated, and submitted to histological examination at varying intervals after the causation of this mild type of injury. Stimulation of the exposed nerve invariably confirmed the presence or absence of motor conduction as observed clinically, and, if the anæsthetic were sufficiently light, confirmed the maintenance of sensory conduction.

Three days after the percussion of the nerve a fusiform swelling had formed at the site of percussion, increasing the diameter of the nerve at this point to as much as 150 per cent. of normal. In very mild lesions the swelling was correspondingly slighter. This swelling was still remarkable after three weeks, and only just discernible after three months, in spite of early complete recovery of conduction. The swelling of "pseudo-neuroma" is due to interstitial œdema and the presence of large numbers of histiocytes in the widened endoneural spaces, in every way identical with that of severe persistent lesions. The œdema lifted the perineurium slightly at the height of the swelling. In the œdematous area the myelin of all large fibres had become greatly swollen and pale, and in some large fibres was in complete dissolution by the third day (Figs. 4A and B), leaving naked axis cylinders (Fig. 4C). The myelin of smaller fibres appeared to be unaffected in osmic preparations. Coarse, darkly staining fatty granules were seen in a moderate number of histiocytes which had appeared in the œdematous endoneural spaces.

Three days after the injury a few axis cylinders in each section showed the frayed appearance we have found to be general in severe, persistent lesions. The remainder were all greatly swollen throughout the pseudo-neuroma reaching diameters of 10 to $12 \mu$ as in Fig. 3D. At the point struck and for a short distance proximal to this the larger axons were distorted in a sinuous fashion, with intermittent pallor or failure of impregnation seen in some fibres in more severe lesions, as in the lower part of Fig. 3c. At either extremity of the pseudo-neuroma these swollen axons abruptly regained a swollen myelin sheath which became of normal appearance when traced a farther 1-2 mm. away from the lesion. Cell stains showed the presence of moderate numbers of histiocytes in the endoneural spaces at this stage and the oval, pale nuclei of the endoneurium were unduly frequent. The Schwann nuclei were distorted, but not otherwise changed. No mitoses of endoneural or Schwann nuclei were seen.

Transverse section of the swelling on the fifth day revealed myelin sheaths in all stages of disappearance at the level of percussion (Fig. 4D). The axis cylinder, unstained, or but slightly darkened in osmic preparations, was sometimes completely denuded of myelin, but more often had a crescentshaped remnant applied to one side as in many of the unstained fibres in Fig. 4D. The residual myelin was swollen and pale except for small foci which were densely blackened by osmic acid. The nerve from which this figure was taken had shown clinical evidence of 50 per cent. loss of motor conduction for two days, with clinical improvement on the third day and no evidence of block of motor conduction on proximal direct stimulation on the fifth (last day).

These charges slowly became intensified. The 

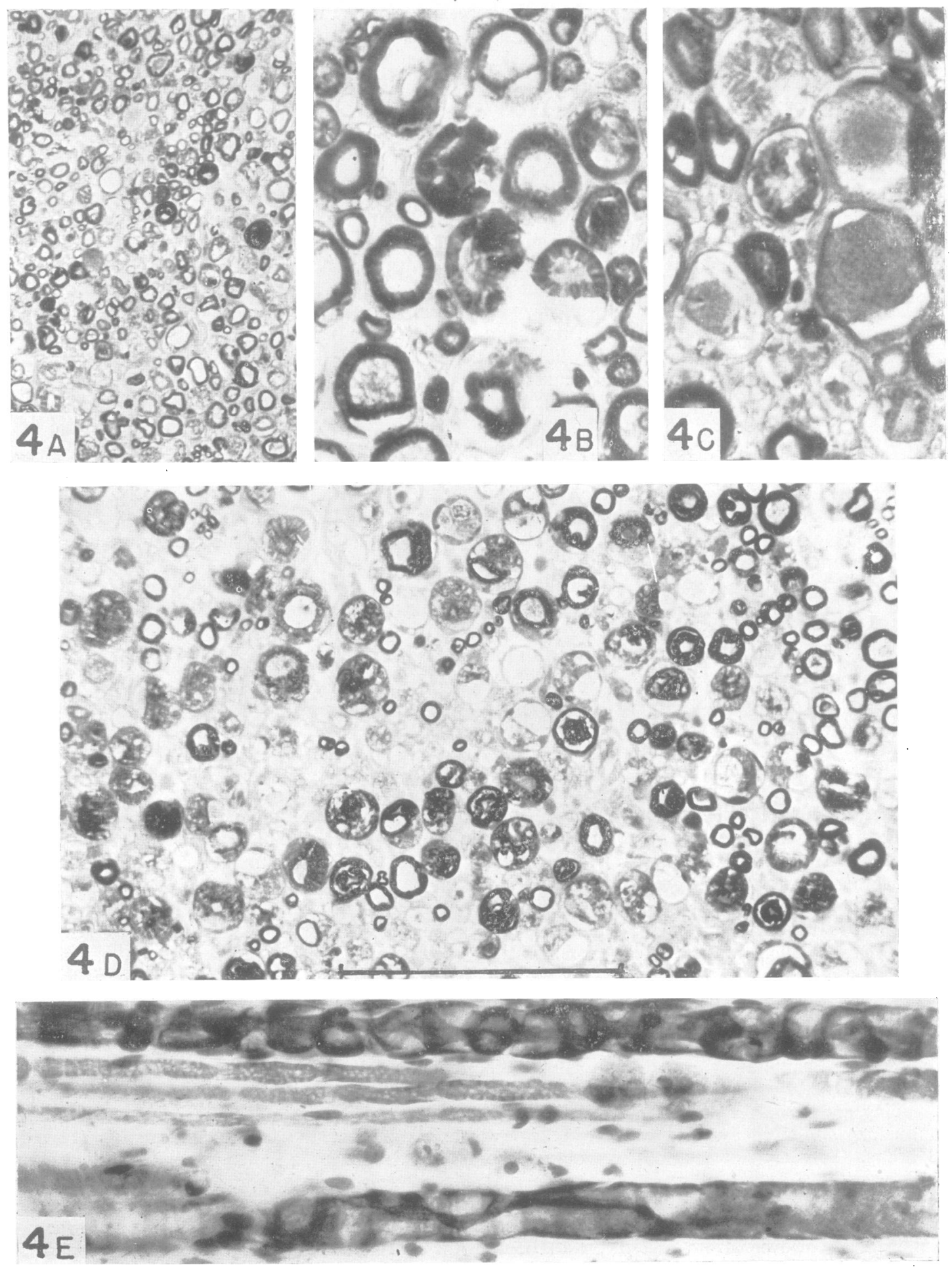

Fig. 4A.-Popliteal nerve. Transverse section of centre of pseudo-neuroma, three days after percussion. Complete motor paralysis until third day, sensation to touch and pinch intact throughout. Osmic acid.

FIG. 4B.-As 4A, higher magnification.
FIG. 4C.-As 4A, higher magnification.

FIG. 4D.-Peroneal nerve five days after percussion. Severe weakness of dorsiflexion of foot, paralysis of spreading recovering after four days. Sensation to pinch throughout. Osmic acid. The ruled line is equivalent to $0 \cdot 1 \mathrm{~mm}$. Fig. 4E.- Peroneal nerve 13 days after percussion. Sudan III, to show two large and three small cedematous myelin sheaths near centre of pseudo-neuroma. The distorted axis cylinders of the large fibres are stained by hæmatoxylin. 

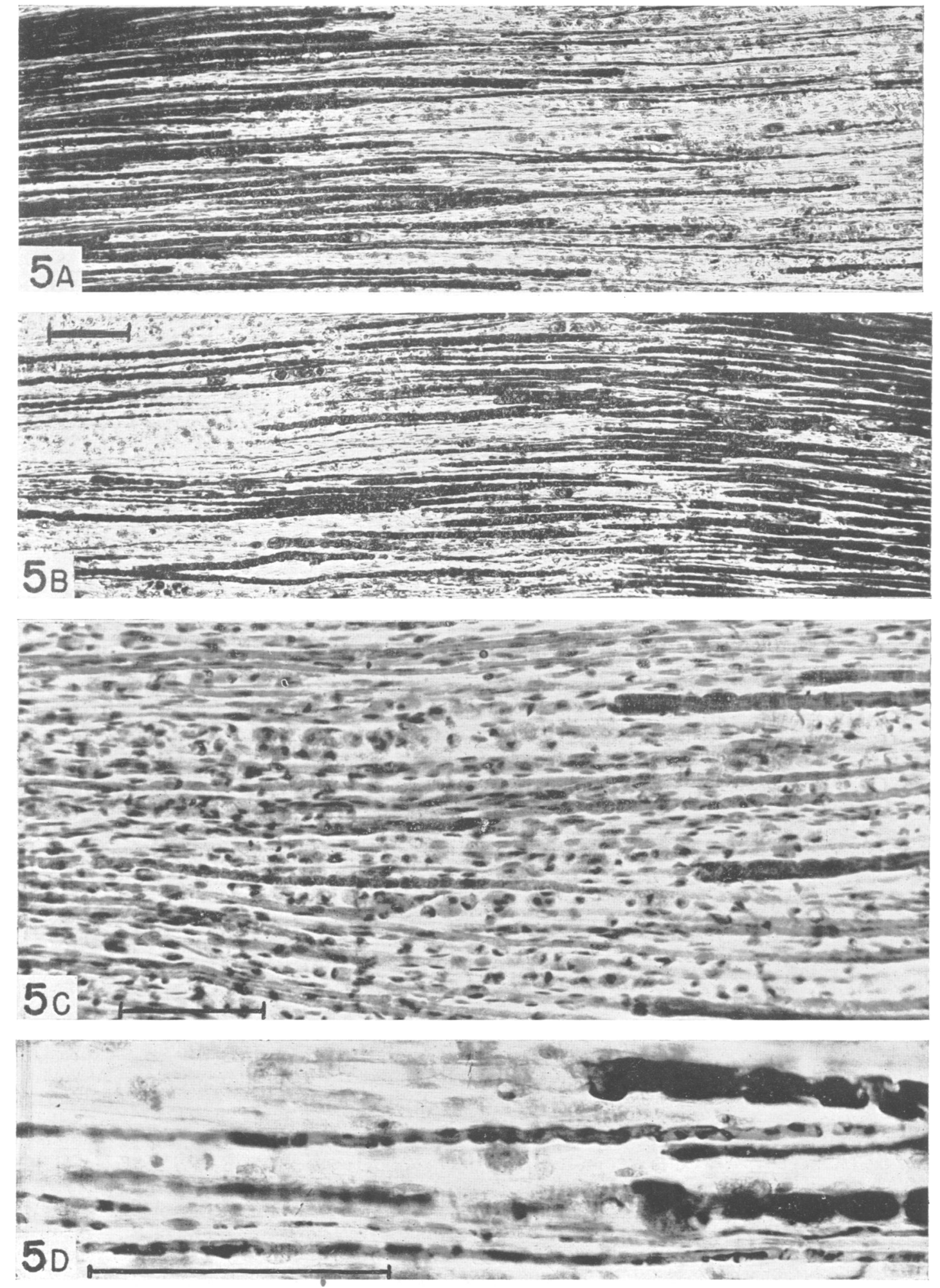

FIG. 5A.-Higher magnification of the proximal extremity of the pseudo-neuroma shown in Fig. 2B to show loss of myelin. Spielmeyer's stain.

FIG. 5B.-The same magnification of the distal extremity of the pseudo-neuroma in Fig. 2B to show recovery of myelin. The ruled line at upper left-hand corner is equivalent to $0.1 \mathrm{~mm}$.

FIG. 5c.-Distal extremity of section of the same pseudo-neuroma to show recovery of myelin, small myelinated fibres and demyelinated axis cylinders. Sudan III hæmatoxylin. The ruled line in the lower left-hand corner is equivalent to $0.1 \mathrm{~mm}$.

FIG. 5D.-Detail of recovery of myelin in two large and one small fibre (at centre), in the distal pseudo-neuroma shown in Fig. 2B, 13 days after injury. An extremely thin film of myelin covers the uppermost demyelinated fibre. Spielmeyer method. The ruled line is equivalent to $0 \cdot 1 \mathrm{~mm}$. 
œdema and cellular reaction reached a maximum fourteen days after the original percussion. At this time axis cylinders appeared more widely separated and the phagocytic histiocytes more numerous (Fig. 2C). Occasional axis cylinders that had been interrupted now showed the plexiform branching with network of proliferated Schwann cells we have described in persistent lesions. These few bundles communicated directly with distal myelin sheaths that displayed commencing Wallerian degeneration. A few axis cylinders were swollen and irregular throughout the lesion but showed no irregularity in depth of staining with silver. The irregularity took the form of numerous projections, as in the large fibre near the top of Fig. 6B. By counterstaining frozen sections stained by the Bielschowsky method with Sudan (Oil Red O) stain for fat, these irregular swollen axons were shown to possess an intact though œdematous myelin sheath throughout the lesion. They were also clearly observed in Sudan sections counterstained with hæmatoxylin (Fig. 4E), and were evidently the "barbed" fibres of Tinel (1917). These intact fibres were present in inverse proportion to the number of degenerate (fibrillar) fibre bands. It was not found possible to obtain a pseudo-neuroma free from both. The bulk of the nerve fibres, however, were strikingly different, for the remaining 70 to 90 per cent. of axis cylinders stained unevenly with silver for a variable extent, and in the combined staining method many could be traced from the point when proximal myelin abruptly ceased to where the distal myelin abruptly recommenced (Figs 6A, B, C, D, and E). The demyelinated gap varied from $0.01 \mathrm{~mm}$. to $1.1 \mathrm{~mm}$. It was not possible to be sure of continuity of fibre in longer gaps which are suggested by sections such as that shown in Fig. 2B. In none of these was there evidence of distal degeneration of myelin, though for a distance up to $1 \mathrm{~mm}$. on either side of the lesion the myelin was swollen and irregular. The peripheral nerve stained with osmic acid usually showed degeneration in fewer than 2 per cent. of fibres, and numerous sections of muscle failed to show degenerated end plates.

The demyelinated segment of axon was a single stout structure with limiting membrane and finely granular contents (Figs. 6C and D). There was always a cellular covering which was more distinct after the seventh day, partly owing to the separation of fibres by increased œdema, partly to collapse of the sheath of Schwann around the naked axon (Figs. 5c and $D$ and Fig. 7). Two weeks after the percussion two types of nuclei accompanied the bared axons. At intervals of approximately 0.1 to $0.2 \mathrm{~mm}$. the narrow darkly staining Schwann nuclei lay closely applied to the axon, usually indenting the surface (Figs. 6C, $D$ and $E$ and $7 \mathrm{~B}$ ). Schwann nuclei, normally distributed so that each one lies in the centre of a segment of about one millimetre, were redistributed between the seventh and fourteenth day so that one lay on the centre of each of the new, shorter and lightly staining, internodal segments.
Various steps in this migration were observed, though mitosis was rarely seen. The young Schwann nuclei were smaller than normal, and had a high affinity for silver, so that in a lightly stained silver preparation only those proliferating nuclei may be stained (Figs. 6C, D, and E).

At similar intervals, but usually more numerous, oval, pale nuclei, lacking the nucleolus usually seen in the Schwann nucleus, lay wrapped around the fibre, often obliquely (Figs. 5C and 7A). Those were usually separated from the axon by a distinct interval, and in places the outline of a membrane could be seen between these pale nuclei and the Schwann nucleus (Fig. 7B). The pale oval nuclei were therefore interpreted as those of endoneural cells. They were readily distinguished from the more narrow pointed nuclei of fibroblasts. Their cytoplasm was rarely stainable and then appeared to be the fibrous endoneural reticulum of Laidlaw. With the Bielschowsky method the cytoplasm of the Schwann nucleus sometimes stains, giving a further differentiation from the endoneural nucleus (Fig. 7c).

The naked segment of axis cylinder did not show fibrillar change and did not branch in any specimen that could be traced into an intact distal myelin sheath. All axis cylinders that began proximally as a single core and more distally showed bifurcation or multiple branching (Fig. 3B) were, if traceable distally, found to enter Schwann tubes containing degenerated myelin. Lateral sprouts or branches were therefore always a sign of interruption of continuity. Proximal to the point of branching such an axon presented the same appearance as a demyelinated but uninterrupted cylinder.

Though increase in number of endoneural cells was observed on the third day the manner in which these cells embrace the demyelinated segment of axon is not clear until after the tenth day, when the Schwann sheath becomes more closely applied to the naked axon. The earlier distension of this sheath appears to be due to œdema and vacuolation. The endoneural cells did not embrace fibres which retained a myelin sheath (Fig. 7A). The penetration of the Schwann sheath by the phagocytic histiocytes, so commonly observed in Wallerian degeneration, was very rarely observed, and then only when some large myelin droplet remained in the Schwann sheath. The histiocytes remained in the endoneural spaces where they collected in large numbers (Figs. 5c, 6A, and 7A), their rounded cytoplasm filled with fatty droplets. Occasional lymphocytes and Mast cells were also seen. There was no evidence of migration of cells or œdema up or down the nerve. The blood vessels in the pseudoneuroma were greatly congested (Fig. 7D) but showed no other change.

The smallest medullated fibres ( 2 to $3 \mu$ in frozen sections) appeared to escape demyelination in passage through the pseudo-neuroma. The myelin in these was often granular and poorly stained (Fig. 5D) by Spielmeyer's stain, but was intact in Sudan and osmic preparations. In the same figure the distal 

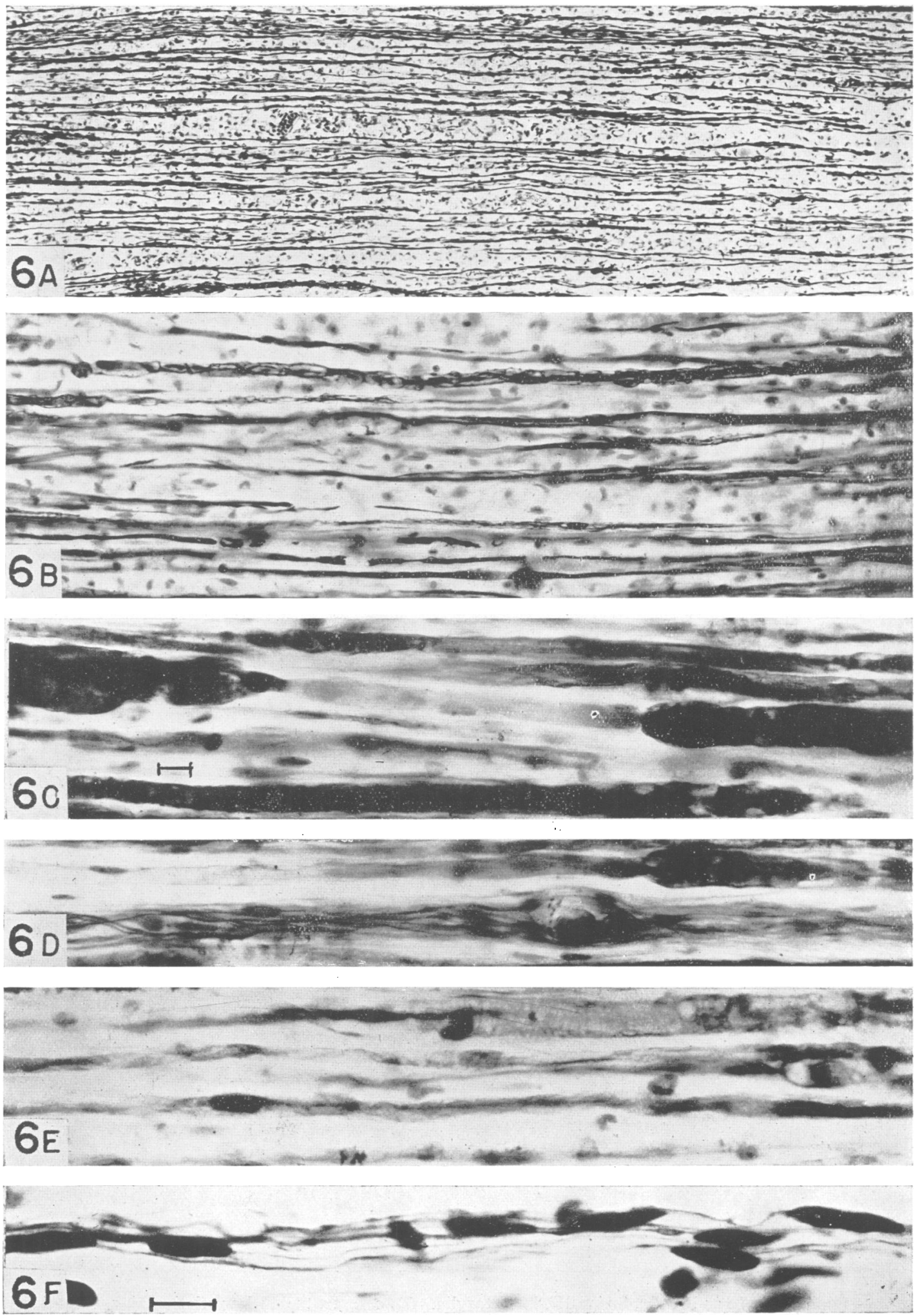

FIG. 6A.-Popliteal nerve. Centre of pseudo-neuroma from same nerve as shown in Fig. 2c, 13 days after injury, 10 days after recovery from severe weakness. Gros-Bielschowsky method.

FIG. 6B.-As 6A, higher magnification from another section, to show penetration of axis cylinder in œdematousmyelin sheath (second from top of figure), demyelinated and beaded axons.

Fig. 6c.-As 6A, to show short segment of demyelinated axon. Gros-Bielschowsky, Sudan III and hæmatoxylin. The small ruled line is equivalent to $0.01 \mathrm{~mm}$.

FIG. 6D.-To show demyelinated axon joining the distal myelin sheath (above), and a regenerating bundle of fibrils (below).

FIG. 6E.-As 6A, to show junction of demyelinated axon with distal myelin sheath and two other naked axons.

FIG. 6P. - As 6A, non-medullated sympathetic fibres with normal Schwann nuclei and areas of oval expansion in the pseudo-neuroma. Gros-Bielschowsky. The small ruled line is equivalent to $0.01 \mathrm{~mm}$. 

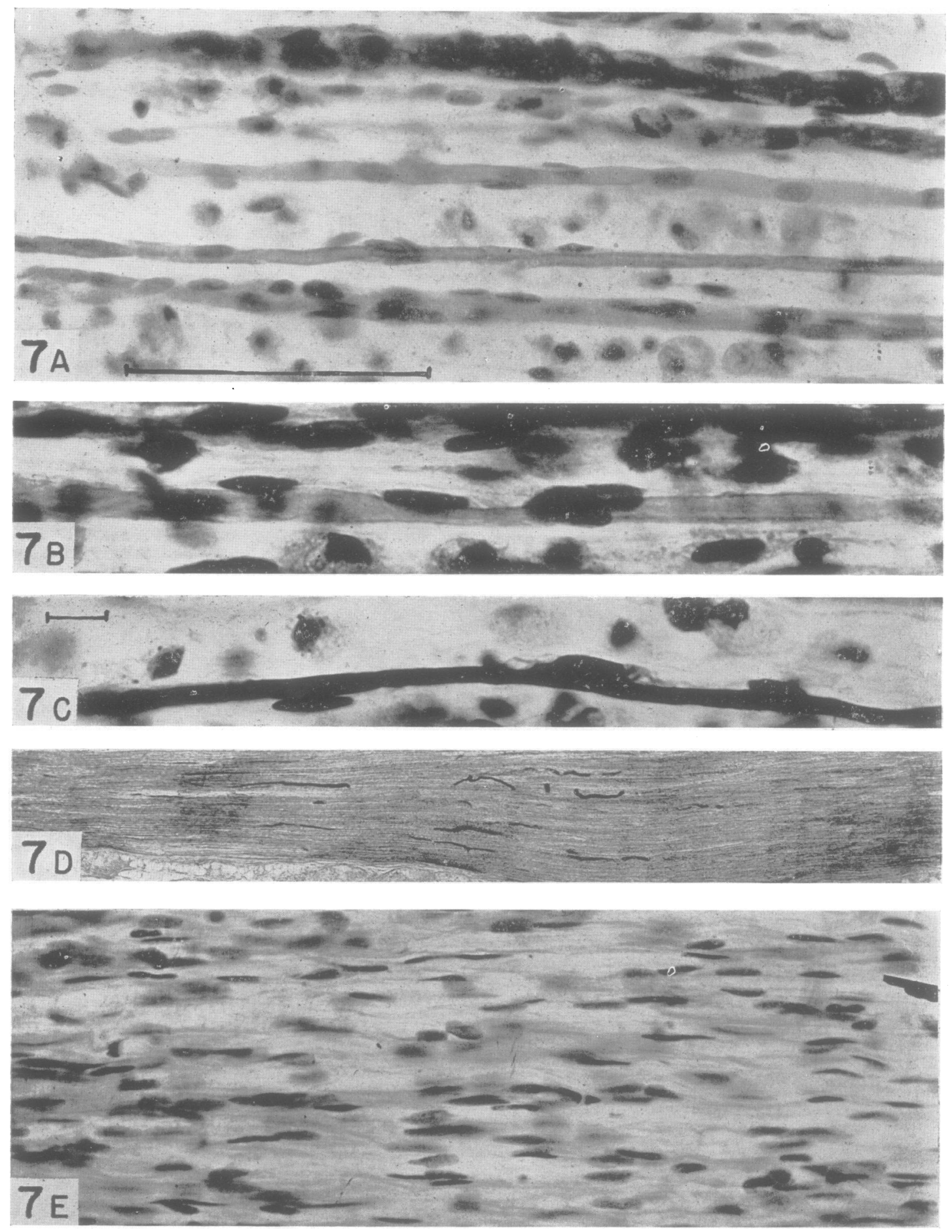

FIG. 7A.-Popliteal nerve as Fig. 5c, Sudan III, hæmatoxylin. To contrast the nuclear relationships of myelinated, but œdematous fibre (above), demyelinated naked axis cylinder (next below), finely myelinated axis cylinder, and Schwann sheath with regenerative proliferation (lowest). The ruled line is equivalent to $0.1 \mathrm{~mm}$.

FIG. 7B.- High magnification of demyelinated axis cylinder. Sudan III and hæmatoxylin to show Schwann nucleus at centre with overlying membrane and endoneural nuclei to right and left clasped around outer (Schwann) membrane. FIG. 7c.-To show cytoplasm of Schwann nucleus (to right of centre) in comparison with lack of staining of cytoplasm of endoneural nuclei (right and left). The ruled line is equivalent to $0.01 \mathrm{~mm}$.

FIG. 7D.-Longitudinal section of region of percussion (to right of centre) three days after injury, to show congested FIG. 7E.-Longitudinal section of region of percussion three months after the sistent endoneural nuclei (pale) and normal distribution of Schwann nuclei. 
end of the demyelinated segment of a moderately small fibre is shown. The demyelinated gap in such fibres was short, as can be seen in Fig. $5 \mathrm{~A}$ where they are seen to run far into the œdematous area before losing myelin. Non-medullated axis cylinders appeared to cross the pseudo-neuroma intact, though oval formations were seen in the fibrils, probably an expression of œdema (Fig. 6F), as in severe lesions. Their Schwann nuclei remained intact.

\section{The Formation of Pseudo-neuroma}

Percussion, whether leading to rupture of axis cylinder or only to transient disorder of conduction, is associated with a precocious and localized breakdown of the myelin sheath. The process of slow ingestion of the myelin tube in the form of globules or " ovoids" by phagocytes, as seen in Wallerian degeneration, does not occur in the percussed region, but is replaced by a rapid dissolution of myelin, complete in three to five days. In that short period enormous numbers of fat granule cells with kidneyshaped or irregular nucleus appear in the tissue spaces, which are widely distended with fluid. The observed swelling of the nerve is directly related to this œdema. The vessels in the œdematous region are widely distended, but show no evidence of thrombosis. There is seldom any hæmorrhage into the endoneurium, and the swelling and other changes are independent of such occurrence. The histological picture is comparable with acute but localized inflammation.. Polymorphonuclear leucocytes do not appear unless in relation to some small and adventitious hæmorrhage.

We found that if at the same exploration at which the nerve was percussed a tight silk ligature was tied $1 \mathrm{~cm}$. or more proximal to the level of percussion all the phenomena of "pseudo-neuroma" could be produced, uncomplicated by the process of regeneration. Thus, three days after the percussion, all the myelin distal to the ligature was still intact and the axis cylinders swollen and irregular, except at the level of percussion. Here there had developed the usual localized swelling with endoneural œdema, and all myelin had disappeared (Fig. 8D). Numerous phagocytes filled the endoneural spaces. The axis cylinders of all sizes had broken into weakly staining fragments or had completely disappeared (Fig. 8E). On either side of the percussed region the axis cylinder was greatly swollen and frequently ended in a rounded, abrupt fashion. The Schwann cells had not proliferated. The appearance was consistent with a great acceleration of lysis and phagocytic activity.

In the course of previous work on compression of nerve (Denny-Brown and Brenner, 1944b) we have observed that the nerve on either side of a compressed area became œdematous and swollen. This change was related by us to vascular stasis. In moderate degrees of compression with dissociated block of conduction the œedematous reaction was also accompanied by a rapid dissolution of myelin and appearance of histiocytes, though these were absent in the odema produced by minimal compressions not causing block. Guttmann and Medawar (1942) note the swelling of a nerve trunk above a ligature and state that such swelling does not develop if an additional ligature be tied 10-20 mm. proximally at the same time as the first, or if the proximal nerve be interrupted by the injection of chromic acid. These authors conclude that in the absence of nerve fibres, a swollen central end-bulb is not formed. Such experiments appear to us, however, to overlook other possibilities, for the vascular supply to the nerve between the ligatures or other obstruction was also abolished by their method. The same objection also appears to us to be inherent in the experiments of Weiss (1943), who, after slipping an arterial cuff over the proximal cut end of nerves, observed a larger swelling of the nerve proximal to the contracted segment of artery than distal to it, and concluded that the process of œdema then arose from obstruction of a centrifugal flow of endoneural and axonic fluids.

We have endeavoured to test these hypotheses by two sets of experiments. The effect of percussion of a section of nerve between two ligatures was examined with and without persistence of blood supply to the isolated segment. The ligatures were placed 10 to $15 \mathrm{~mm}$. apart, and arranged so that in some experiments the isolated segment received the lower branch of the sciatic artery and vein, in others no blood supply. Without blood supply the isolated segment of nerve becomes shrunken and yellowish in colour in 14 days. There is some adherence to surrounding tissue. Percussion in the middle of the segment at the time of ligature had left no local swelling. Sections revealed only a uniform necrosis of all nerve structure. If the isolated segment were allowed to retain a blood supply from a branch of sciatic artery and vein it became somewhat swollen as a whole with greater swelling next each ligature. Percussion in the centre of the segment a few moments after the ligatures were tied had resulted in a small localized swelling at the percussed level fourteen days later. Within this swelling there was precocious disappearance of all myelin and axis cylinder remnants, and a localized intensity of histiocyte response with œdema. Further, if the proximal ligature was placed so that the nerve trunk received direct branches of sciatic vessels on either side the swelling occurred on the two sides of the ligature, perhaps more often a little less in degree on the distal side as Weiss has observed. Weiss concludes that the distal swelling is not œdema because the nerve fibres are not separated by fluid. We also found less endoneural fluid below the ligature, but we observed that the fibres themselves were more œdematous, being in process of degeneration.

The vascular supply to nerve trunks involves a longitudinal anastomosis between widely spaced tributaries, no one of which is essential for metabolism at any level. As we have recently described (Denny-Brown and Brenner, 1944a) ligature of pudic, sciatic and popliteal vessels to the sciatic 
nerve in cats results only in patchy œdema without disturbance in function. The experiments described above, however, indicate that œdematous swellings related to ligature or other compression are greater when closely related to the entry of a vascular tributary, and we consider this to indicate that they are primarily derived from vascular factors.

The precocious disappearance of myelin in association with the localized œdema following percussion raises a further problem. The œdema requires an intact vascular supply. Is the oedema part of an inflammatory response to traumatic breakdown of myelin, or is the primary damage vascular and increased phagocytosis and myelin dissolution related to ischæmia?

\section{Percussion of Degenerated Nerve}

We proceeded to degenerate the sciatic nerve by section between two ligatures, allowing the sciatic artery to give direct supply to the distal segment. After an interval of three weeks for degeneration, the nerves were re-explored and the distaldegenerated segment was percussed. After intervals of 3 and 14 days, the animals were killed and the nerves examined.

The effect of percussion of degenerated nerve was remarkable. Although no pseudo-neuroma was observed after intervals of 3 and 14 days, in frozen sections some slight increase of the odema of the percussed region was present in comparison with the remainder of the degenerated nerve. The arrangement of macrophages and their general appearance was considerably changed in the damaged area. The change was most evident in frozen sections stained by Sudan III for fat (Figs. 9A and $\mathrm{B})$. The macrophages were no longer vacuolated and compressed into the well-known " ovoids" of Wallerian degeneration, where the borders of one cell are difficult to distinguish from its neighbour. The macrophages in the percussed area instead lay free, with rounded cytoplasm filled with fat granules. The vacuoles had disappeared. The nucleus was larger and had lost the distortion typical of " foam cells." They had taken up an arragement in parallel lines, a re-arrangement that is obvious also in the bands of Bungner, which were also converted into parallel columns in the affected region (Fig. 9D) instead of the meshwork in which they contain Wallerian ovoids (Fig. 9c). Since this change was fully accomplished in three days and was confirmed in $\mathrm{H}$ and $\mathrm{E}$, and Mallory phosphotungstic preparations, and since an occasional remnant of ovoid was rarely found, it was concluded that the macrophages had in fact been freed by the injury. All histologists have agreed that the macrophages present in Wallerian ovoids are "so compressed that the intercalary spaces are often obliterated" (Cajal, 1928). The source of this pressure has not been determined. The dramatic release of all the macrophages by a single sudden trauma indicates, however, that the Schwann tube, confining these phagocytes, was ruptured by the trauma, following which the macrophages came to lie in the endoneural space. The rapid disappearance of the characteristic vacuoles is also remarkable, and indicates that they are related to the previous tension. Whether the confining membrane is the neurilemma (wall of the Schwann tube) or an endoneural sheath is open to conjecture. We are in agreement with Holmes and Young (1942) that the neurilemma remains distinct in degenerated nerve, and in stained sections found no evidence that the endoneurium in such nerves confines the Schwann cell more completely than in a normal nerve.

Experiments on the effect of percussion of degenerated nerve therefore show that the effect of such trauma is then traceable to rupture of the Schwann tube. The "foam cell" then becomes an ordinary macrophage. The great odema peculiar to a percussed normal nerve is absent. It is therefore concluded that the œdema and phagocytic reaction of the pseudo-neuroma is determined primarily by traumatic breakdown of myelin. From the appearance of splits in the myelin three days after percussion of normal nerve (Fig. 4B), and the remarkable decompression of phagocytes in degenerated nerve, it appears reasonable to assume that rupture of the neurilemma occurs in both instances by longitudinal splits, and that the tissue reaction in normal nerve is due to contact of myelin with endoneurium. Such rupture would also explain the precocious spread of leashes of neurofibrillar strands into the endoneurium and their later atrophy, an occurrence which at first we were at a loss to understand. It even appears possible that at the moment of the blow axis cylinder and myelin flow laterally through ruptures in the neurilemma.

\section{Rupture of the Perineurium}

In some experiments, immediately following percussion, a small white herniation appeared on the nerve at the point struck. This was likely to happen if the surfaces of the striking object and of the plate underlying the nerve were not parallel, so that the momentary compression of the nerve bundle was more to one side. The perineurium had ruptured and allowed nerve fibres to bulge through the opening. In such an experiment, where the peroneal division had developed such a hernia, the nerve was sectioned after 14 days' survival, paralysis of spreading and of dorsiflexion of the foot having been observed to persist, the swelling of the peroneal and popliteal divisions appeared to be that usually encountered. On section a proliferation of endoneurium, perineurium and nerve fibres through the opening was seen to have occurred (Fig. 10A and $\mathrm{B})$. The spindle-shaped swelling on the peroneal nerve was partly a true neuroma. Myelinated fibres with irregular neurofibrillar regeneration bulged through the opening (Fig. 10A). The myelin in the remainder of the bundle was swollen and irregular on all fibres. Demyelination, leaving naked axis cylinders, was present in scattered fibres, throughout the unherniated portion (Fig. 10c) with a high proportion of regeneration. Though endoneural 

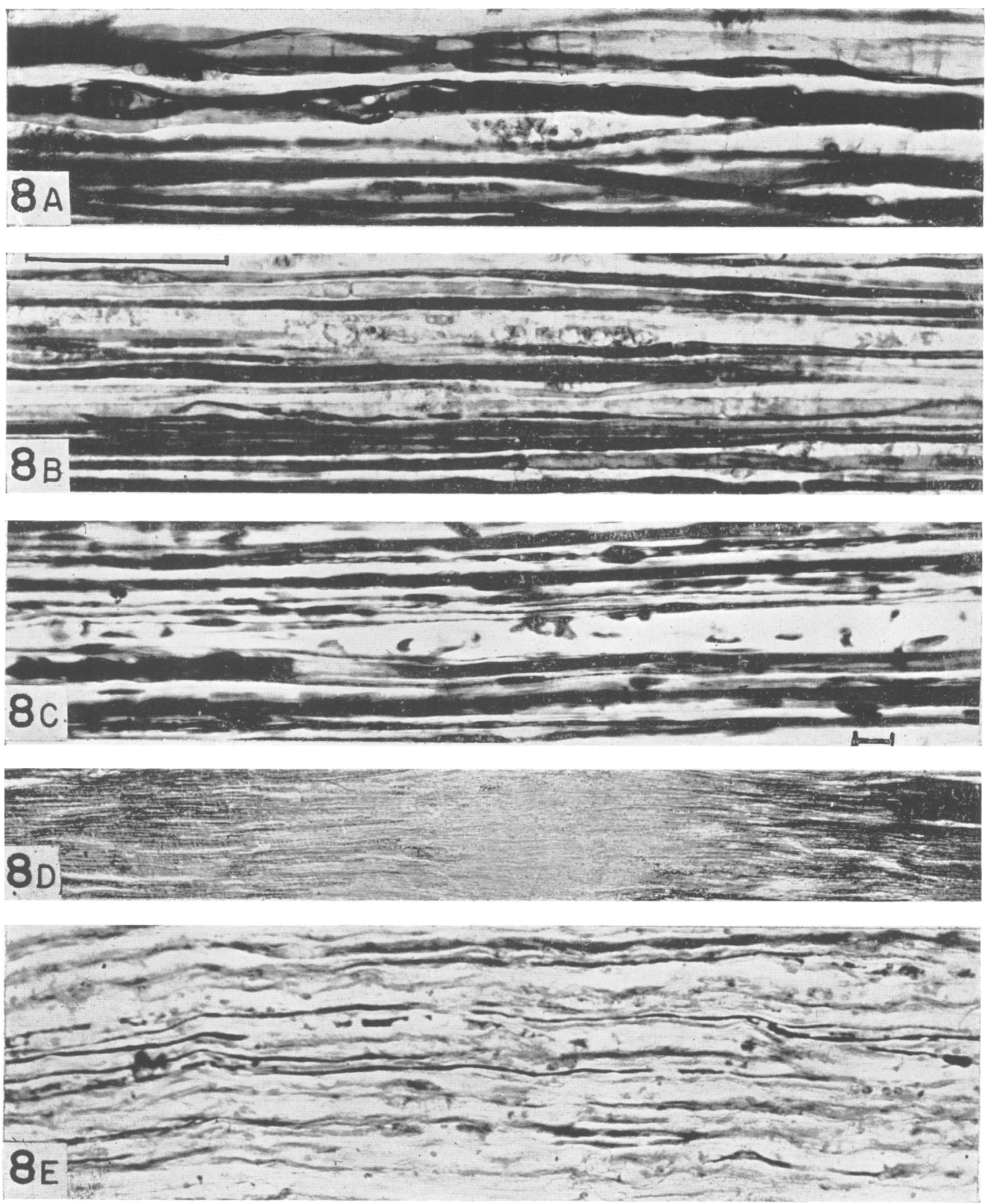

Fig. 8A.-Sciatic nerve at level of severe percussion three months earlier, causing severe paralysis for 30 days with complete recovery in 60 days. Spielmeyer's method to show very thin myelin sheath and small branches in uppermost fibre.

FIG. 8B.-Popliteal nerve three months after mild percussion causing partial weakness for three days, to show thin

myelination at level of injury (no change distally). The ruled line is equivalent to $0 \cdot 1 \mathrm{~mm}$.
FIG. 8c.-As 8B. Gros-Bielschowsky method for axis cylinders to show irregularity of staining. The ruled line is equivalent to $0.01 \mathrm{~mm}$.

FIG. 8D.-Popliteal nerve, percussed three days earlier and ligatured $2 \mathrm{~cm}$. proximal to level of section. Iron hæmatoxylin. To show loss of myelin at level of percussion.

FIG. 8E.-As 8D. Gros-Bielschowsky method at level of percussion. 

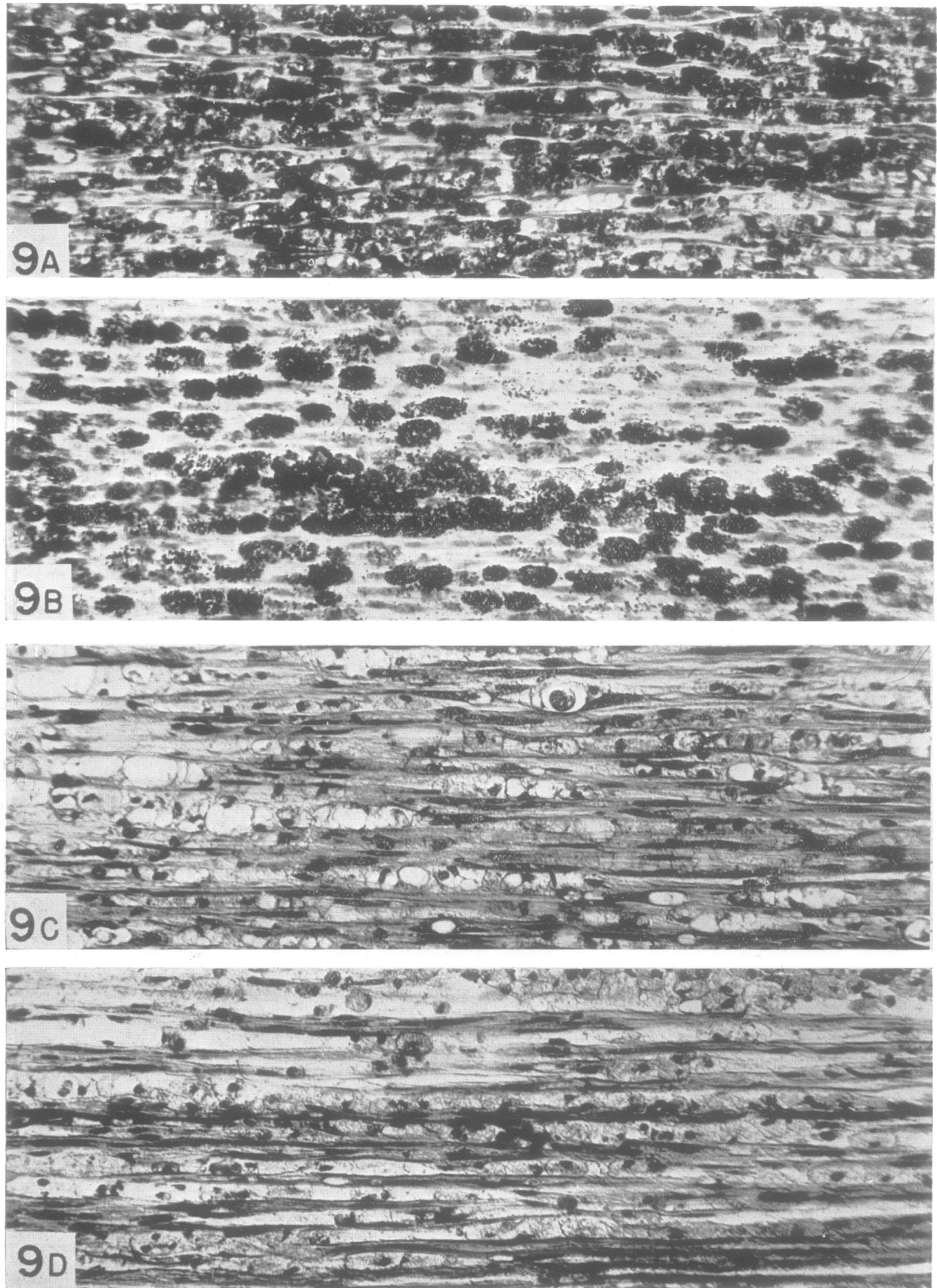

FIG. 9A.-Sciatic nerve, Sudan III, 24 days after section between ligatures $4 \mathrm{~cm}$. proximal to region shown. FIG. 9B.-As 9A, but $1 \mathrm{~cm}$. farther distally, where the nerve had been percussed three days previously.

FIG. 9C.-As 9A, phosphotungstic acid hæmatoxylin.

FIG. 9D.-As 9B, phosphotungstic acid hæmatoxylin. 
œdema was much less than in a pseudo-neuroma the naked axis cylinders were greatly swollen. Histiocyte response was present throughout the nerve at this level, but these cells were closely packed between the nerve fibres. There had therefore been spontaneous decompression of the perineurium. In other examples encountered it was observed that degeneration of all the fibres herniated through the opening and many of those near it had occurred by the fifth day. In one example, kept for six weeks, the proliferation of the hernia resulted in the formation of a large spindle-shaped mass with profusion of branching fibrils. There was still no evidence of recovery. Experiments of longer duration are in progress.

\section{Discussion}

Percussion of peripheral nerve evokes a tissue response characterized by localized vascular stasis and œdema, with the appearance of large numbers of histiocytes and with proliferation of endoneurium. The myelin for a millimetre or more on either side of the level of percussion undergoes dissolution, and the histiocytes in the endoneural œdema become filled with fat droplets. This process is complete in three to five days. It differs completely from the chief histological feature of Wallerian degeneration, where phagocytes enter the sheath of Schwann and slowly ingest large globules or segments of myelin in the course of 2-25 weeks. Doinikow (1911), however, observed that in Wallerian degeneration some solution of myelin also took place, with the appearance of fat in surrounding endoneural cells and histiocytes. The rapid disintegration of all myelin by a process of solution following percussion is, however, sufficiently distinct to merit special attention. It closely resembles the rapid dissolution of myelin in a segment of nerve that has been frozen, as described by Bielschowsky and Valentin (1922). We have recently (Denny-Brown and Brenner, 1944b), described an identical dissolution of myelin consequent on compression of nerve, these being related to the effect of ischæmia under and immediately distal to the compressing agent. In that case there was also œdema and inflammatory response. In mild degrees the ischæmic lesion was associated with preservation of axis cylinders, and a block of conduction of motor fibres.

In the experiments here described a moderate degree of percussion led to localized disappearance of myelin without anatomical interruption of axis cylinders. Disturbance in function was then chiefly if not entirely related to motor conduction, and, though complete for three to four days, made rapid recovery. This milder type of lesion resembles the ischæmic lesion induced by compression, though it is of briefer duration. The possibility of a common mechanism in both compression and percussion lesions therefore arises.

Though percussion of a degree sufficient to cause impairment of conduction often led to some effusion of blood into the adventitia of the larger veins in the epineurium, these hæmorrhages are insignificant in relation to the remainder of the lesion and the changes described were independent of them. In other experiments, sub-perineural hæmorrhage, induced by gentle kneading, has in any case been found to be innocuous. No evidence of thrombosis of vessels was found early or late after percussion. All vessels in the affected area were greatly congested. If the perineurium was ruptured by the original injury the swelling or pseudo-neuroma was decompressed by the rupture, with herniation of endoneurium and nerve fibres through the tear. The damage to the myelin and the cellular response, however, still occurred throughout the nerve, though not to the same extent. The naked axis cylinders were then greatly swollen. Demyelination therefore does not depend directly on the internal pressure developed by œdema confined within intact perineurium, though it was less extensive when perineural rupture had occurred, nor does spontaneous decompression prevent the appearance of the fibrillary regeneration of some fibres throughout the nerve bundle. Lastly, whereas compression of nerve affected all sizes of nerve fibres alike (Denny-Brown and Brenner, 1944b), the demyelination from percussion was in all but the most severe degree selective for the largest myelinated fibres.

Escape of some of the largest fibres from demyelination, as in Fig. 2B, was related to slight asymmetry of the lesion, for they then lay to one or other side of the nerve bundle. In general we were satisfied that in the percussion lesion the measurable extent of demyelination in any given fibre bore a relation to the size of fibre, and was thus longest in the largest fibres. In ischæmic lesions the demyelinated gaps were by contrast surprisingly uniform in length (Denny-Brown and Brenner, 1944a and $b$ ). The ischæmic lesion also lacked the Schwann cell proliferation which was a late feature in the percussion lesion, and the demyelinated axon stained less well with silver. The essential nature of the percussion response, however, appeared to be the same in all kinds of medullated nerve fibres and varied only in extent. Non-medullated nerve fibres often presented a beaded appearance in passing through a pseudo-neuroma, but this in some specimens was the result only of a series of oval swellings on each such fibre, and was sometimes seen in fine medullated fibres. It is possibly only an expression of œdema.

The finding of preservation of sensory conduction, even to light touch in one experiment, where no myelin was found to pass continuously across the pseudo-neuroma, indicates that the dissociation of conductile function was not merely the presence or absence of demyelination. The rapid recovery of function, in spite of persistence of the histological change, also warns against close identification of loss of conduction with loss of myelin. We have already indicated a similar discrepancy in ischæmic lesions. It was notable that the transient motor paralysis, when partial, was more complete for distal muscles (spreading), a feature which is probably related to the finding in partial lesions in human 

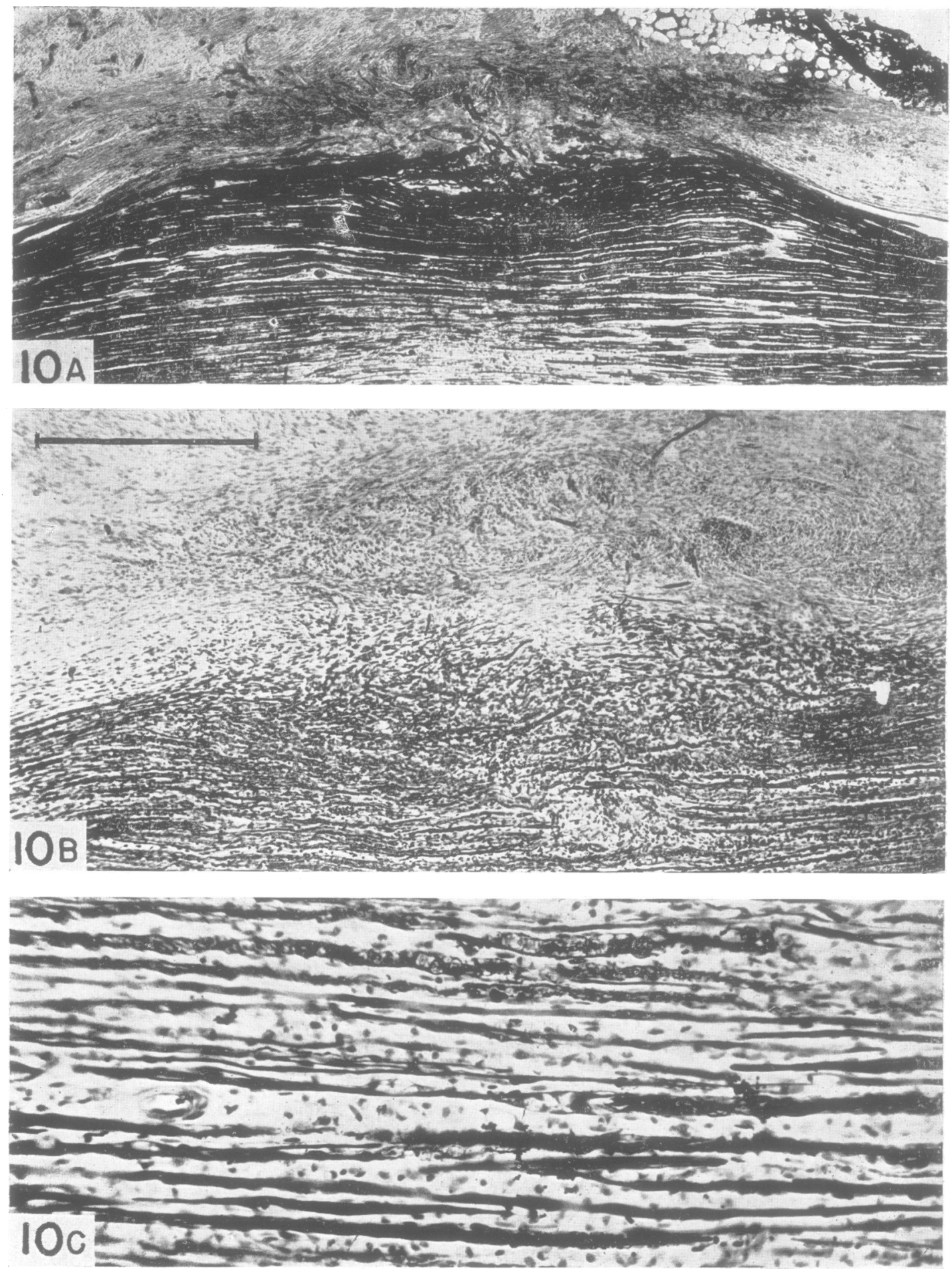

FIG. 10A.-Peroneal nerve at midsciatic level. Percussion with herniation through perineurium 12 days earlier. Spielmeyer's method for myelin. To show the herniation and decompression.

Fig. 10B.-As 10A. Gros-Bielschowsky method. The ruled line is equivalent to $0.5 \mathrm{~mm}$.

FIG. 10c.-Fibres in the centre of the nerve in 10A stained by Gros-Bielschowsky method. 
nerves that the proximal muscles may recover rapidly, the distal only after long delay or not at all (Claude and Dumas, 1917, Platt, 1921). Though it is tempting to relate such disturbance to selective effect of fibre size the evidence is lacking at present.

Seddon (1943) has recently introduced the term neurapraxia to describe disturbances in which paralysis occurs from a nerve injury which does not result in peripheral degeneration. The transient disturbances of function following percussion of nerve fall into this category. On account of the differences between the transient disturbance produced by percussion, and that of ischæmia or compression, we prefer to use the term neurapraxia for the clinical phenomeonon in cases of nerve injury when the actual mechanism is unknown. We have also avoided the use of the term contusion, for this implies the presence of extravasated blood, which is not an essential part of the percussion lesion. We have in fact been able to demonstrate that intrafascicular bleeding does not disturb function, if produced by kneading or other gentle physical manœuvre. The red blood corpuscles are hæmolysed and rapidly absorbed.

The initial mechanism of stasis and histiocyte response requires explanation. The almost complete absence of additional œdema and cellular change following percussion of degenerated nerve, and the striking mobilization of the histiocytes then already jresent, led to the conclusion that percussion led to rupture of the sheath of Schwann. Longitudinal continuity of the Schwann tube was retained, so that such rupture must therefore have been a longitudinal splitting. The argument is also applicable to the immediate disturbance of intact nerve by percussion. Splits in the myelin and Schwann sheath were observed on the third day. The breakdown of myelin is stated to release powerful tissue irritants such as cholesterol and thus induce stasis and histiocyte response in the central nervous system (Marsden and Hurst, 1932). This irritative phenomenon in peripheral nerve can also be related to breakdown of myelin by rupture of the Schwann sheath. Some of the bizarre bulbs, sprays, and sidebranches of the axis cylinder which lie in the endoneurium at the level of a severe percussion may also represent herniations of the axon through the Schwann sheath at the time of injury. Like acute inflammatory reactions in other tissues the stasis and histiocyte response fail to appear in the absence of an intact blood supply. We have presented evidence that the fluid is not derived from any circulation of normal endoneural fluid, and once present does not migrate proximally or distally.

We have found the "barbed" axis cylinders and fibrillary cords described by Tinel (1917), and recognize the former as œdematous fibres still retaining myelin, the latter as regenerating fibrils. We have in addition described the truly demyelinated but otherwise intact axis cylinder, the survival of which is associated with brief block of motor nerve impulses. The lesion is never as pure as the compression lesion. A small proportion of degenerated fibres, and a larger proportion of intact myelination, is always present. An initially complete paralysis was associated with some degeneration, an incomplete paralysis with some unaffected fibres, but the number in each case was very small, and allows transient paralysis to be attributed to demyelination. It will be noted that the loss of myelin is apparent for two to three weeks after a four-day paralysis, and that the renewed myelin film was not observed earlier than the thirteenth day. We have noted this disparity between the slow process of remyelination and return of function in relation to ischæmic lesions also (Denny-Brown and Brenner, $1944 a$ and $b$ ).

Apart from the œdema and tissue response pseudo-neuroma is distinguished from true neuroma by the parallel disposition of nerve fibres, whether they be the remaining " barbed " œdematous axons, the fibrillary bundles which betoken regeneration, or the demyelinated, single axis cylinders. This parallelism indicates that the sheath of Schwann has not ruptured transversely. If the axon is ruptured, regeneration occurs with great rapidity, associated with a profusion of secondary sprouts within the same sheath and proliferation of Schwann cells. Though most of the finer branches adopt a spiral course, the intricate spirals of Perroncito do not occur, and such lesser spirals as are seen are rapidly resorbed. Some branches run centripetally, and these already present resorptive knobs by the fourteenth day. The true Perroncito spiral is formed almost entirely of recurrent centripetal branches, indicating resistance to centrifugal progress. Further, though resorption of the interrupted axis cylinder is very rapid in the pseudoneuroma (in three days following percussion below a ligature), one of the regenerative branches had frequently penetrated far into the peripheral nerve by the fourteenth day, and at the level of the pseudoneuroma had already attained nearly the proportions of a mature axon. In contrast, a true neuroma presents essentially a confusion of direction of nerve fibres, which, with the persistent Perroncito spirals, indicates a transverse disruption of the sheaths of Schwann.

The œdema associated with pseudo-neuroma is accompanied by a brisk endoneural reaction. Though increase in number of the pale endoneural nuclei has been observed in simple œdema of nerve without damage to the nerve fibres (Denny-Brown and Brenner, 1944b), they are particularly clearly defined in relation to demyelinated but intact axons. The Schwann nuclei also proliferate, but to a less remarkable degree and at a later stage. Long after restitution of myelin the pale, oval nuclei of endoneural cells lie in the interspaces between the nerve fibres and mark the original site of the pseudoneuroma. The endoneural cells are then presumably those that surrounded the naked axon in the acute stage of the lesion.

When the original lesion had been sufficiently severe to be followed by a paralysis lasting until regeneration occurred, a similar increase in number 
of endoneural nuclei surrounds the fibrillary bundle of a regenerating axon in a pseudo-neuroma, and is then less obvious only because of the greater proliferation of Schwann cells. A persistent spindleshaped swelling marked the site of percussion after as long as three months. The nerve fibre and sheaths were reconstituted (Fig. 8A), but occasional phagocytes and a large number of endoneural cells and fibres filled the dilated endoneural spaces. The phagocytes were fewer than in the degenerated peripheral segments. The tissue reaction is more intense than in the transient type of lesion. We were not able to identify additional fibroblasts. The traumatic neuroma of "traumatic ulnar neuritis" where trauma is repetitive, is likely to be the cumulative effect of repetition of either mild or severe degree of this process. The gross overgrowth in the endoneural spaces then strangulates the nerve fibres. Such a condition does not appear to arise as a result of a single percussion.

These findings throw some additional light on the phenomena of regeneration of nerve. They indicate that the phagocytic cells, which are attracted by degenerating myelin, are true histiocytes, probably derived from Maximow's " polyblasts " as Nageotte (1932) asserts. The "foam cell" appearance of the Wallerian ovoids is but another aspect of the same phagocytic "Kornzellen" (Doinikow, 1911) which lie free in the endoneural odema. Neither is derived from the Schwann cell. Edema of nerve is a characteristic result of trauma as in other tissues, and we find no evidence of migration of fluid or phagocytes either proximally or distally. It is difficult to concede the possibility of an endoneural or perineural circulation in the absence of such migration. The subsequent resorption of regenerative neurofibrillar outgrowths, excluding that that has been successful, is also clearly indicated. This phenomenon was suspected by Cajal (1928), and was clearly observed in the present experiments. It would appear desirable to investigate the influence of such abortive branches upon function of the conductor concerned, for such branching is the only histological evidence which suggests a clue to the phenomenon of hyperæsthesia. The behaviour of endoneural cells in covering the naked axis cylinders indicates a role previously confused with fibroblastic reaction. The phenomenon appears to have importance in the genesis of true neuroma, and demonstrates an essential difference between the endoneural cell and mesoblastic elements.

Rupture of the perineurium is an event which was more prone to occur if there had been asymmetry in percussion of the nerve, so that the momentary compression occurred more on one side than the other. Although the subsequent œdema was absent or greatly lessened, the histological and functional - disturbance consequent upon such rupture was disastrous for nerve fibres near the resulting hernia. Nerve fibres, Schwann cells, endoneurium and perineurium proliferate through the gaping opening. There is formed a true neuroma with a characteristic tangle of fibres and cells. The neuroma may be lateral and single, or multiple, but fused to the fasciculus in such a way as to make it spindleshaped. Except for some greater adherence to surrounding tissue it was usually indistinguishable from pseudo-neuroma to the naked eye. It was associated with great disorder of conduction of sensation and movement in some fibres for longer than six weeks, which is longer than the usual duration of paralysis from severe uncomplicated percussion at the midsciatic level. This delay in regeneration is related 'to the malalignment of Schwann tubes due to the perineural hernia, and to the great degree of lateral fibrillary and endoneural proliferation thus brought about. Even when the hernia is single and small the remainder of the nerve fibres in the nerve show the patchy demyelination characteristic of percussion lesion, with corresponding partial or complete block. All combinations between the pseudo-neuroma and multiple perineural herniation are therefore to be expected. This complication is likely to be the cause of late neuroma in cases such as that described by Maculaire and Navarre (1915), in which a projectile passed near the median nerve, but did not touch it, and yet a large neuroma resulted.

The descriptions of "spindle neuromata," found in association with prolonged partial disorder of function, and particularly with causalgia, suggests that multiple perineural rupture in the fasciculi which make up the nerve trunk may well be the mechanism of such residual disability. The disturbance of function associated with simple pseudoneuroma was in contrast repaired extremely rapidly and effectively. We therefore suggest that, though repeated mild trauma may lead to permanent overgrowth of endoneurium, and consequent cumulative impairment of function, a single percussion of nerve can produce disorder in function lasting beyond the period of regeneration only through perineural rupture.

\section{Conclusions}

1. A single percussion of a nerve trunk resulted primarily in damage to the myelin sheath, probably with longitudinal rupture of the Schwann sheath and escape of damaged myelin into the endoneural spaces. The axis cylinder escaped interruption if the blow was moderate. Even in the most severe blows the axis cylinders of the finest medullated fibres and non-medullated fibres were not interrupted, and consequently did not degenerate. The sheath of Schwann was not divided transversely by intensities of blow sufficient to disrupt both myelin and axis cylinder.

2. A localized swelling or pseudo-neuroma developed rapidly at the site of injury and persisted for some weeks. The swelling was due to œdema, associated with the rapid appearance of large numbers of histiocytes. This reaction was related to the breakdown of myelin, and occurred if regeneration was prevented by a proximal ligature.

It was prevented by interruption of blood supply.

3. In a moderate degree of lesion, when naked 
axis cylinders of all sizes remained intact, there was retention of sensation with transient complete block of impulses in motor fibres. The smallest medullated fibres escaped or were less severely affected. Non-medullated fibres were then beaded but not interrupted. The dissociation in function closely resembled that caused by ischæmia, though hyperæsthesia to touch was more prominent, and recovery of motor conduction occurred more rapidly. Both the degree of œdema and extent of demyelination were lessened if the œdema was decompressed by concomitant rupture of the perineurium. Some ischæmia was therefore presumed to accompany the œdema and stasis, but was not an essential feature of the mechanism of the lesion.

4. The phagocytic reaction was derived from histiocytes. The Schwann cells played no part in the phagocytic process which was fully developed at the end of the first week when the Schwann nuclei began moderate proliferation along a demyelinated axon, or more profuse multiplication within the tube of a regenerating axon. The endoneural cells surrounded the isolated Schwann sheaths and remained in increased numbers even three months later when myelin structure was nearly completely reconstituted. This increase of endoneural cells was minimal in ultimate degree after a single percussion.

5. Transient paralysis lasting three to four days without loss of gross sensation was the effect of a partial lesion. A pseudo-neuroma was then also present. The majority of axis cylinders had lost myelin in passing through the lesion, but recovered it below. The extent of loss was greatest in the largest fibres. The characteristics of the demyelinated axon are described.

6. If the axis cylinder was transversely interrupted by the percussion, degeneration occurred in the distal portion of the nerve fibre. Regeneration was then extremely rapid (four to eight weeks) and complete. Such regeneration of axis cylinders in intact Schwann tubes involved an initial production of a large number of fibrils by the parent axis cylinder. Early maturation of one of these, pre- sumably that which penetrated farthest, was followed by progressive resorption of the remainder.

7. Delay in regeneration resulted only when the perineurium was ruptured by the percussion. Herniation of nerve fibres and endoneurium then occurred, with true neuroma formation.

8. Percussion of a nerve trunk in process of Wallerian degeneration resulted in liberation of intratubal phagocytes (Wallerian ovoids). The phagocytes then assumed the characters of free fat granule cells. The mechanism of liberation appeared to be traumatic splitting of the Schwann tube.

\section{REFERENCES}

Bielschowsky, M., and Valentin, B. (1922). J. Psychol. Neurol., Lpz., 29, 133.

Cajal, S. Ramon y. (1928). Degeneration and Regeneration of the Nervous System. Trans. by R. May, London.

Claude, H., and Dumas, R. (1917). Bull. Soc. méd. Hôp., Paris, 33, 626.

Dejerine, J., Dejerine, Mme., and Mouzon, M. J. (1915). Pr. méd. No. 31, 245.

Denny-Brown, D., and Brenner, C. (1944a). Arch. Neurol. Psychiat., Chicago, 51, 1. (1944b). Ibid., 52, 1.

Doinikow, B. (1911). Histol. u. histopath. Arbeiten v. Nissl-Alzheimer, Jena, $4,445$.

Guttmann, L., and Medawar, P. B. (1942). J. Neurol. Psychiat., 5, 130.

Holmes, W., and Young, J. Z. (1942). J. Anat., London, $77,63$.

Maculaire and Navarre (1915). Paris. méd., 17, 378.

Marsden, J. P., and Hurst, E. W. (1932). Brain 55, 181.

Medical Research Council Special Report Series No. 54. The Diagnosis and Treatment of Peripheral Nerve Injuries, London, 1920.

Mitchell, S. Weir (1872). Injuries of Nerves and their Consequences, Philadelphia.

Nageotte, J. (1932). In Section V, of Cytology and Cellular Pathology of the Nervous System, Vol. I, edited by Wilder Penfield, New York.

Platt, H. (1921). The Surgery of the Peripheral Nerve Injuries of Warfare, Bristol.

Seddon, H. J. (1943). Brain, 66, 237.

Tillaux, P. (1866). Des Affections Chirurgicales des Nerfs, Thèse de Paris.

Tinel, J. (1917). Nerve Wounds. Symptomatology of Peripheral Nerve Lesions Caused by War Wounds. Trans. by Rothwell, F., and Joll, C. A., London.

Tubby, A. H. (1915). Brit. med. J., 1, 57.

Weiss, P. (1943). Anat. Rec., 86, 491. 